\title{
Frequent Episodes of Detectable Viremia in HIV Treatment-Experienced Children is Associated with a Decline in CD4+ T-cells Over Time
}

\section{Elijah Paintsil ${ }^{1 \#, ~ R y a n ~ M a r t i n ~}{ }^{2 \#}$, Ariel Goldenthal ${ }^{3}$, Shreya Bhandari ${ }^{4}$, Warren Andiman ${ }^{5}$ and Musie Ghebremichael ${ }^{6 *}$}

${ }^{1}$ Departments of Pediatrics and Pharmacology, Yale University School of Medicine, New Haven, USA

${ }^{2}$ Georgetown University, Washington, DC, USA

${ }^{3}$ Columbia University College of Physicians and Surgeons, New York, USA

${ }^{4}$ Tufts University, Medford, USA

${ }^{5}$ Department of Pediatrics, Yale University School of Medicine, New Haven, USA

${ }^{6}$ Ragon Institute and Harvard Medical School, Cambridge, MA

"Equally Contributed

\begin{abstract}
Background: The clinical consequences of the magnitude and the duration of detectable viremia in HIV-infected children have not been well characterized. We examined the predictors and immunologic consequences over time of frequent episodes of detectable viremia in HIV-infected children followed at Yale-New Haven Hospital.
\end{abstract}

Methods: We analyzed the CD4+ T-cell and HIV viral load over a 19-year period (1996 to 2013) of 104 HIVinfected children enrolled in the Yale Prospective Longitudinal Pediatric HIV Cohort. Both CD4+ T-lymphocytes and HIV viral load were measured at clinic visits every 3 to 4 months. Longitudinal data analyses using polynomial random coefficients models were conducted to examine overtime changes in CD4+ T-cell counts by frequency of episodes of detectable viremia. Moreover, regression analyses using logistic regression models were used to assess the predictors of frequent episodes of detectable viremia.

Results: One hundred and four (104) HIV-infected children with more than one HIV viral load measurement between 1996 and November 2013 were included in the analysis. Over $80 \%(N=86)$ of the children had detectable viral load (HIV RNA viral load $\geq 50$ copies $/ \mathrm{ml}$ ) during more than $50 \%$ of their clinic visits. Children with infrequent episodes of detectable viremia had significantly higher CD4+ T-cell counts overtime compared to those with frequent episodes of detectable viremia $(P<0.0001)$.

Conclusions: Both frequency and magnitude of episodes of detectable viremia had effect on CD4+ T-cells. Strict adherence to a treatment goal of undetectable HIV viremia in children is likely to be beneficial.

Keywords: HIV-infected children; CD4+ T-Cell; Transient viremia; Virologic failure; Viral blips

\section{Background}

The management of the pediatric HIV epidemic is one of several HIV success stories; despite this, progress has not been uniform worldwide. At the end of December 2013, only $23 \%$ of the 3.2 million children estimated to be living with HIV were receiving antiretroviral therapy (ART) and in 2013 alone, 240000 were newly infected and 190 000 (170000-220000) died of HIV-related causes [1]. ART coverage in children varies from country to country, ranging from $20 \%$ to $>95 \%$ [2]. The goal of ART is to suppress HIV viral replication and restore immune function (i.e., CD4+ T-cell recovery). Uncontrolled HIV viremia leads to depletion of CD4+ T-cells with a concomitant increase in risk for opportunistic infections, AIDS, and death [3-5].

HIV RNA levels vary in individual patients; this variation is greater in children than in adults [6-8]. HIV RNA $>500$ copies/mL after having formerly achieved virologic suppression is generally accepted as virologic failure [9-11]. However, isolated episodes of plasma HIV RNA $>500$ copies $/ \mathrm{mL}$ (i.e., transient viremia) followed by return to levels of viral suppression often observed in adults and children on ART are not considered as virologic failure $[9,12,13]$. Transient viremia is relatively common among children on ART $[12,14]$. The underlying mechanisms and clinical consequences of transient viremia are debatable. A number of mechanisms have been implicated, including variable sensitivity of viral load assays [15], random statistical and biological variations [16], opportunistic infections [17], activation of latently infected cells [18], nonadherence to ART [19], and evolution of drug resistant viruses [20,21]. The clinical significance of episodes of transient viremia has evoked mixed reports. While some studies have reported that transient viremia are of no clinical significance $[16,22,23]$, others studies have reported an association between transient viremia and virologic failure [9,24,25], depletion of CD4+ T-cells [26], and emergence of drug resistant viruses [20,21].

However, there is a paucity of data on the clinical significance of transient viremia in children. The higher variability and natural ageassociated decline of CD4+ T-cells seen in children may limit the extrapolation of findings of clinical significance of transient viremia in adults to children [27]. The main objectives of our study were to examine the predictors of frequent episodes of detectable viremia and the association between frequent episodes of detectable viremia and CD4+ T-cell changes over time in children.

\section{Methods}

\section{Study participants}

Longitudinal data were extracted from the Yale Prospective

*Corresponding author: Musie Gebremichael, $\mathrm{PhD}$, Ragon Institute and Harvard Medical School; 400 Tech Square, Room 857, Cambridge, MA 02129, USA, Tel: 857-268-7006; E-mail: musie_ghebremichael@dfci.harvard.edu

Received March 22, 2016; Accepted April 07, 2016; Published April 14, 2016

Citation: Paintsil E, Martin R, Goldenthal A, Bhandari S, Andiman W, et al. (2016) Frequent Episodes of Detectable Viremia in HIV Treatment-Experienced Children is Associated with a Decline in CD4+ T-cells Over Time. J AIDS Clin Res 7: 565. doi:10.4172/2155-6113.1000565

Copyright: (C) 2016 Paintsil E, et al. This is an open-access article distributed under the terms of the Creative Commons Attribution License, which permits unrestricted use, distribution, and reproduction in any medium, provided the original author and source are credited. 
Longitudinal Pediatric Cohort study at Yale-New Haven Hospital. The rationale, organization, and recruitment of the subjects for the cohort study have been described previously [28]. In brief, the enrollment of children born to HIV-1-infected mothers in the greater New Haven area in Connecticut began in 1985. All the children either had mothers already known to be HIV-1 seropositive during pregnancy or at the time of delivery or were discovered to be infected with HIV-1 after presenting with an AIDS defining illness. In the analyses contained herein, we used data collected from HIV-infected children from January 1996, when plasma HIV-1 RNA quantification became available, to November 2013. The study protocol was reviewed and approved by Institutional Review Board at Yale School of Medicine. No informed consent was obtained since patient information was anonymized and de-identified prior to analysis.

Study variables: The outcome variables of the study were absolute CD4+ T-cell count and HIV-1 viral load. The predictor variables included, gender, race, age at study entry, age at HIV diagnosis, caregiver type, history of AIDS defining illness, time since HIV diagnosis, CDC clinical staging of HIV infection, and baseline CD4 T-cell count.

Definitions: Detectable viremia was defined as any detectable viral load above the limit of detection of the assay [29]; we used either 50 or 500 copies $/ \mathrm{mL}$ as the cutoff viral load. The study participants were divided into two categories based on the frequency of episodes of detectable viremia during scheduled clinic visits.

Infrequent episodes of detectable viremia: This category comprised individuals who had detectable viremia during less than $50 \%$ of their clinic visits.

Frequent episodes of detectable viremia: This category comprised individuals who had detectable viremia during more than $50 \%$ of their clinic visits.

\section{Clinic and follow-up visits}

The study participants were seen and examined at the pediatric specialty clinic every three to four months. Since 1996, HIV-1 RNA quantification and CD4+ T- cell counts and percentages were done at every clinic to follow HIV disease progression. The Amplicor Monitor ${ }^{\mathrm{ry}}$ test (Roche Diagnostic Systems, Inc., Branchburg, New Jersey, USA) was used for the quantification of the HIV-1 RNA, in accordance with the manufacturer's instructions and the AIDS Clinical Trials Group (ACTG) quality assurance recommendations were followed, as described elsewhere [30]. The assay's detection limit was 500 copies $/ \mathrm{mL}$ and 50 copies/mL, before 2004 and after 2004, respectively. CD4+ T-cells were quantified by standard dual-platform flow cytometry technology by a certified clinical laboratory at Yale-New Haven Hospital.

\section{Statistical analysis}

Descriptive measures were used to summarize the data. Continuous variables were summarized using median and inter quartile range (IQR); categorical variables were summarized using frequency and percent (\%). Wilcoxon rank sum and Fisher's exact tests were used to compare continuous and categorical variables, respectively, between subjects with infrequent and frequent episodes of detectable viremia. Regression analyses using logistic regression models were used to estimate the odds of having frequent episodes of detectable viremia. Longitudinal data analyses using polynomial random coefficients models were conducted to examine differences in CD4+ T-cell counts by frequency of episodes of detectable viremia. Two-sided p-values are reported for all the statistical tests used in the analysis.

\section{Results}

One hundred and four (104) HIV-infected children with more than one HIV viral load measurement between 1996 and November 2013 were included in the analysis. The demographic and HIV disease characteristics of the study participants are described in Table 1. Fifty four percent were males, 59\% were African Americans, and 57\% had biological parents as caregivers. The majority of the participants had congenital HIV (93\%), moderate to severe CDC classification (65\%), and other comorbidities (55\%).

The study participants were divided into two categories based on the frequency of episodes of detectable viremia over the study period. The 'infrequent' category comprised individuals who had detectable viremia, viral load above the detection limit of the assay, during less than $50 \%$ of their clinic visits. The 'frequent' category comprised individuals who had detectable viral load during more than $50 \%$ of their clinic visits. When the limit of detection of the assay was $<50$ copies $/ \mathrm{ml}$, more than $80 \%(\mathrm{~N}=86)$ of the children had frequent episodes of detectable viremia. Table 1 shows the characteristics of the study population stratified by the frequency of episodes of detectable viremia. There were no statistically significant differences in patient characteristics between the two categories.

Figure 1A displays the odds of having frequent episodes of detectable viremia with corresponding $95 \%$ confidence intervals.

\begin{tabular}{|c|c|c|c|c|}
\hline & \multirow[b]{2}{*}{ All $(\mathrm{N}=104)$} & \multicolumn{2}{|c|}{ Detectable viremia } & \multirow[t]{2}{*}{ P-value } \\
\hline & & $\begin{array}{l}\text { Infrequent } \\
(\mathrm{N}=18)\end{array}$ & $\begin{array}{l}\text { Frequent } \\
(\mathrm{N}=86)\end{array}$ & \\
\hline \multicolumn{5}{|l|}{ Study covariates } \\
\hline & Median (IQR) & & & \\
\hline Baseline CD4 $/ \mathrm{mm}^{3}$ & $436(125-725)$ & $550(26-820)$ & $420(140-663)$ & 0.48 \\
\hline Baseline VL $\left(\log _{10}\right)$ & $4.79(4.13-5.32)$ & $4.60(2.60-5.50)$ & $4.79(4.20-5.18)$ & 0.85 \\
\hline $\begin{array}{l}\text { Age at study entry } \\
\text { (years) }\end{array}$ & $7.83(5.02-11.98)$ & $7.74(3.70-13.07)$ & $7.83(5.20-11.76)$ & 0.92 \\
\hline $\begin{array}{l}\text { Age at diagnosis } \\
\text { (years) }\end{array}$ & $1.79(0.44-4.91)$ & $2.04(0.21-5.32)$ & $1.79(0.52-4.91)$ & 0.82 \\
\hline \multirow{2}{*}{$\begin{array}{l}\text { Time since } \\
\text { Diagnosis (years) }\end{array}$} & $5.14(2.32-7.35)$ & $3.03(0.60-8.88)$ & $5.42(2.52-7.32)$ & 0.40 \\
\hline & $N(\%)$ & & & \\
\hline Gender & & & & 1.00 \\
\hline Female & $48(46 \%)$ & $8(44 \%)$ & $40(47 \%)$ & \\
\hline Male & $56(54 \%)$ & $10(56 \%)$ & $46(53 \%)$ & \\
\hline Race/Ethnicity & & & & 0.80 \\
\hline Black & $61(59 \%)$ & $10(56 \%)$ & $51(59 \%)$ & \\
\hline Other & $43(41 \%)$ & $8(44 \%)$ & $35(41 \%)$ & \\
\hline Other Illness & & & & 1.00 \\
\hline No & $43(45 \%)$ & $7(47 \%)$ & $36(44 \%)$ & \\
\hline Yes & $53(55 \%)$ & $8(53 \%)$ & $45(56 \%)$ & \\
\hline Caregiver & & & & 0.79 \\
\hline Parent & $59(57 \%)$ & $11(61 \%)$ & $48(56 \%)$ & \\
\hline Other & $44(43 \%)$ & $7(39 \%)$ & $37(44 \%)$ & \\
\hline \multicolumn{5}{|l|}{$\begin{array}{l}\text { Mode of } \\
\text { transmission }\end{array}$} \\
\hline Congenital & $97(93 \%)$ & $15(83 \%)$ & $82(95 \%)$ & 0.10 \\
\hline Other & $7(7 \%)$ & $3(17 \%)$ & $4(5 \%)$ & \\
\hline CDC Classification & & & & 0.37 \\
\hline N: None & $14(13 \%)$ & $4(22 \%)$ & $10(12 \%)$ & \\
\hline A: Mild & $23(22 \%)$ & $3(17 \%)$ & $20(23 \%)$ & \\
\hline B: Moderate & $30(29 \%)$ & $3(17 \%)$ & $27(31 \%)$ & \\
\hline C: Severe & $37(36 \%)$ & $8(44 \%)$ & $29(34 \%)$ & \\
\hline
\end{tabular}

Table 1: Characteristics of study participants stratified by frequency of detectable viremia. 
Although race/ethnicity, baseline $\mathrm{CD} 4+\mathrm{T}$-cell count, and time since diagnosis did not reach statistical significance, they were associated with the frequency of detectable viremia. The odds of having frequent episodes of detectable viremia was $34 \%(\mathrm{OR}=1.34$, 95\% CI: 0.44-4.06) higher in black children compared with children from other races. Moreover, the odds of having frequent episodes of detectable viremia diminished by $21 \%(\mathrm{OR}=0.79,95 \% \mathrm{CI}: 0.48$ $1.30)$ in children with higher baseline CD4+ T-cell count (per 1-SD increase in baseline CD4 counts) compared with children with lower baseline CD4+ T-cell count.

Individual growth models were used to explore participant's longitudinal CD4+ T-cell data over time. Figure $1 \mathrm{~B}$ displays the empirical growth plot of CD4+ T-cell data with average trend lines (smooth) included for the two detectable viremia categories. The trend lines show that the CD4+ T-cell values for both groups slowly increased from baseline values and decreased at later time points over the study

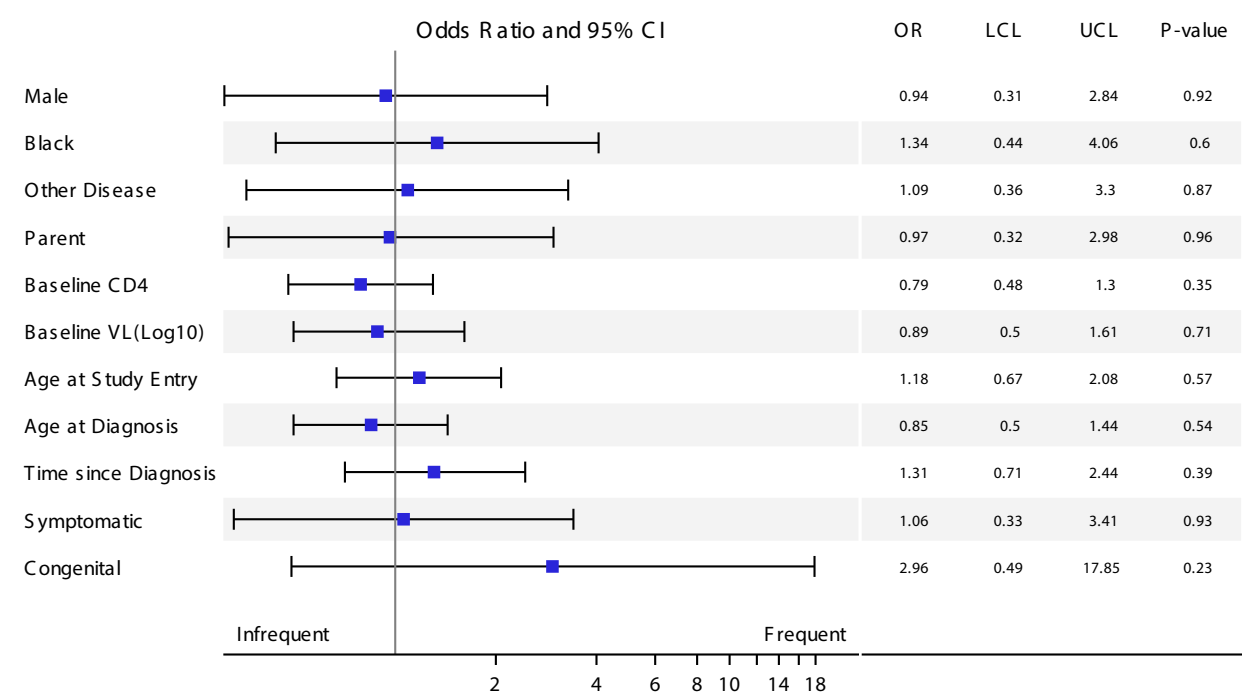

Figure 1A: Risk factors for frequent episodes of detectable viremia among children in Yale-New Haven Hospital.

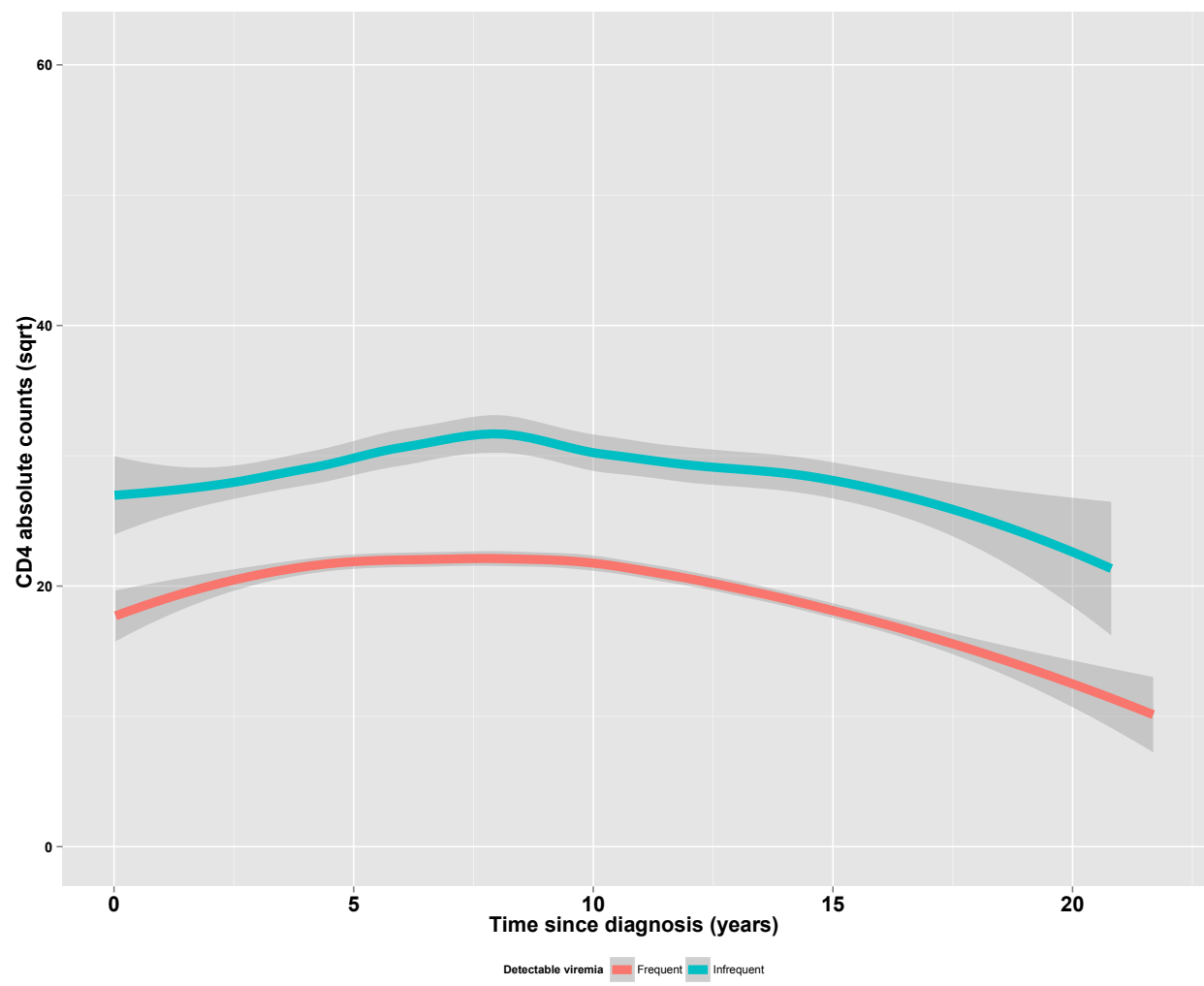

Figure 1B: CD4+ T-cell count trajectories by frequency of detectable viremia status among children in Yale-New Haven Hospital. 
period. Since the trend lines were curvilinear, a quadratic random coefficients model was applied. The likelihood ratio test indicated that the quadratic model fits the data better than the linear model $\left(\left(\mathrm{c}^{2}=461\right.\right.$, $\mathrm{df}=9-6, \mathrm{P}<0.0001)$ and hence results of the quadratic model are reported here. Children with infrequent episodes of detectable viremia had significantly higher CD4+ T-cell counts over time compared with those with frequent episodes of detectable viremia $(\mathrm{P}<0.0001)$. The mean square root of the CD4+ T-cell count since HIV diagnosis was 29.13 (95\% CI:25.43-32.85) cells $/ \mathrm{mm}^{3}$ in the infrequent group and 20.05 (95\% CI: $18.43-21.66$ ) cells $/ \mathrm{mm}^{3}$ in the frequent group. The rate of change in CD4+ T-cell count depended on time in both groups: 2.43-2.45T in the infrequent group and $0.52-0.07 T$ in the frequent group, where, $\mathrm{T}$ denotes time from HIV diagnosis. Though the rate of change of the average CD4+ T-cell count over time was not statistically different between the two groups ( $\mathrm{p}=0.10)$, the rate was higher in the infrequent group. We also conducted a sensitivity analysis using a cutoff of 500 copies $/ \mathrm{mL}$. This definition is more reflective of individuals with viremia between 50 to 500 copies $/ \mathrm{mL}$. The findings from our sensitivity analyses were identical to that reported above using 50 copies $/ \mathrm{mL}$ as cutoff (data not shown).

\section{Discussion}

We found that frequent episodes of detectable viremia were common in our pediatric cohort. Of the $104 \mathrm{HIV}$-infected children who were enrolled in the study, more than $80 \%(\mathrm{~N}=86)$ had frequent episodes of detectable viremia ( $>50$ copies $/ \mathrm{mL}$ ) during the course of the study. Moreover, there was an inverse relationship between frequency of detectable viremia and CD4+ T-cell trajectory. The odds of having frequent episodes of detectable viremia were $30 \%$ higher in black children compared with children from other races. Higher baseline CD4+ T-cell count was associated with less frequent episodes of detectable viremia. Throughout the study period, children with infrequent episodes of detectable viremia had significantly higher CD4+ T-cell counts.

Our finding of inverse correlation between frequency of episodes of detectable viremia and CD4+ T-cell is consistent with findings from previous studies in adults [26,31-33]. Boufassa et al. reported that viral blips in HIV controllers were associated with a significant decline in CD4+ T-cells [26]. This is consistent with our finding; however, viral blips was defined as any detectable viral load above the limit of detection offered by the assay preceded and followed by an undetectable viral load measurements [29]. Since some of our patients had missing values at random, we did not apply this definition. We rather chose a more liberal and real world definition of any detectable viremia during clinic visits regardless of the interval. Furthermore, Di Mascio et al. reported a negative correlation between frequency of viral blips and baseline CD4+ T-cell counts [31]. Martinez et al. observed that patients with frequent viral blips had lower CD4+ T-cell counts after 12 and 18 months of therapy [32]. They also reported that the frequency rather than the magnitude of the blips was associated with impaired CD4+ T-cell count recovery. We observed that both frequency and magnitude of viral blips had an effect on CD4+ T-cells. Interestingly, other studies have reported that viral blips predate virologic failure $[9,24,25]$. Virologic failure often results in faster decline of CD4+ T-cells and subsequent AIDS-related clinical events [26]. Our finding, might have resulted from both viral blips and true virologic failures.

Our findings have implications for pediatric ART monitoring in both resource-rich and resource-limited countries. In general, HIVinfected children are less likely than infected adults to achieve full viral suppression on ART [34-36]. Viral load monitoring is not routine in resource-limited countries. The 2013 WHO HIV treatment guidelines define virologic failure as plasma viral load above 1000 copies $/ \mathrm{mL}$ on two consecutive measurements three months apart in individuals adherent to medication use (www.who.int/hiv). From our finding, this cutoff may be too high, thereby leading to high prevalence of virologic failure and subsequent $\mathrm{CD} 4+\mathrm{T}$-cell decline. Moreover, early virologic failure may be missed, resulting in evolution of drug resistant HIV variants in HIV-infected children in sub-Saharan Africa [37,38]. Further studies on the clinical significance of frequency of episodes of detectable viremia in HIV-infected children are needed to inform appropriate cutoffs for virologic failure.

Our study has several strengths compared with previous studies. It is a large population-based study, enhancing its generalizability and it is one of the few studies on frequency of episodes of detectable viremia in children. However, the study has several limitations. First, it spans a period of nineteen years during which time HIV medicine underwent rapid and complex changes in treatment regimens. Since these changes were not envisaged at the inception of the cohort study, critical treatment data are missing, making it difficult to assess the direct impact of the components of various regimens on viremia and CD4+ T-cell counts. Also, viremia during non-adherence may have different consequences from that during complete adherence [9]. Second, our definition of frequency of episodes of viremia is quite liberal; however, in the absence of a consensus on the definition of viral blips, our findings are consistent with other studies using various definitions of viral blips.

\section{Conclusions}

In conclusion, strict adherence to ART with the goal of undetectable HIV viremia in children is likely to be beneficial. Frequent viral loads above the detection limit of the assay may lead to unintended persistent viremia with subsequent virologic failure, decline in $\mathrm{CD}+\mathrm{T}$-cell count, and evolution and spread of drug resistant HIV variants.

\section{Authors's contributions}

EP, RM, WA, and MG designed the study. RM and MG analyzed the data. EP, RM and MG wrote the article. AG, WA SB revised the article. All authors read and approved the final article.

\section{Acknowledgements}

We thank the clinical team of the Pediatric AIDS Care Program for providing specialized medical care and social work services for the children enrolled. We thank the children and families who participated in the HIV prospective longitudinal pediatric cohort study. The study was supported by grants from Harvard University Center for AIDS Research (HU CFAR NIH/NAIDS P30-AI 060354) to MG and the Ragon Institute of MGH, MIT and Harvard to MG, RM and AG; National Institute of Child Health and Human Development (5 N01 HD 3-3345), National Institute of Allergy and Infectious Disease (AI32397 and AI39015) to WA; and NIH/NICHD grant R01HD074253 to EP.

\section{References}

1. WHO (2014) Optimizing treatment options and improving access to priority products for children living with HIV.

2. WHO/UNICEF/UNAIDS (2014) Global AIDS Response Progress Reporting.

3. Vlahov D, Graham N, Hoover D, Flynn C, Bartlett JG, et al. (1998) Prognostic indicators for AIDS and infectious disease death in HIV-infected injection drug users: plasma viral load and CD4+ cell count. JAMA 279: 35-40.

4. Nishanian P, Taylor JM, Manna B, Aziz N, Grosser S, et al. (1998) Accelerated changes (inflection points) in levels of serum immune activation markers and CD4+ and CD8+ T cells prior to AIDS onset. J Acquir Immune Defic Syndr Hum Retrovirol 18: 162-170.

5. Pantaleo G, Graziosi C, Fauci AS (1993) New concepts in the immunopathogenesis of human immunodeficiency virus infection. $N$ Engl $J$ Med 328: 327-335. 
6. Hughes MD, Johnson VA, Hirsch MS, Bremer JW, Elbeik T, et al. (1997) Monitoring plasma HIV-1 RNA levels in addition to CD4+ lymphocyte count improves assessment of antiretroviral therapeutic response. ACTG 241 Protocol Virology Substudy Team. Ann Intern Med 126: 929-938.

7. Raboud JM, Montaner JS, Conway B, Haley L, Sherlock C, et al. (1996) Variation in plasma RNA levels, CD4 cell counts, and p24 antigen levels in clinically stable men with human immunodeficiency virus infection. $\mathrm{J}$ Infect Dis 174: 191-194.

8. Navér L, Ehrnst A, Belfrage E, Sönnerborg A, Lidin-Janson G, et al. (1999) Long-term pattern of HIV-1 RNA load in perinatally infected children. Scand J Infect Dis 31: 337-343.

9. Grennan JT, Loutfy MR, Su D, Harrigan PR, Cooper C, et al. (2012) Magnitude of virologic blips is associated with a higher risk for virologic rebound in HIVinfected individuals: a recurrent events analysis. J Infect Dis 205: 1230-1238.

10. Karlsson AC, Younger SR, Martin JN, Grossman Z, Sinclair E, et al. (2004) Immunologic and virologic evolution during periods of intermittent and persistent low-level viremia. AIDS 18: 981-989.

11. Aleman S, Söderbärg K, Visco-Comandini U, Sitbon G, Sönnerborg A (2002) Drug resistance at low viraemia in HIV-1-infected patients with antiretroviral combination therapy. AIDS 16: 1039-1044.

12. Lee KJ, Shingadia D, Pillay D, Walker AS, Riordan A, et al. (2007) Transient viral load increases in HIV-infected children in the U.K. and Ireland: what do they mean? Antivir Ther 12: 949-956.

13. Coovadia A, Abrams EJ, Stehlau R, Meyers T, Martens L, et al. (2010) Reuse of nevirapine in exposed HIV-infected children after protease inhibitor-based viral suppression: a randomized controlled trial. JAMA 304: 1082-1090.

14. Siberry GK, Harris DR, Oliveira RH, Krauss MR, Hofer CB, et al. (2012) Evaluation of viral load thresholds for predicting new World Health Organization stage 3 and 4 events in HIV-infected children receiving highly active antiretroviral therapy. J Acquir Immune Defic Syndr 60: 214-218.

15. Stosor V, Palella FJ Jr, Berzins B, Till M, Leake A, et al. (2005) Transient viremia in HIV-infected patients and use of plasma preparation tubes. Clin Infect Dis 41: 1671-1674.

16. Nettles RE, Kieffer TL, Kwon P, Monie D, Han Y, et al. (2005) Intermittent HIV-1 viremia (Blips) and drug resistance in patients receiving HAART. JAMA 293: 817-829.

17. Jones LE, Perelson AS (2005) Opportunistic infection as a cause of transient viremia in chronically infected HIV patients under treatment with HAART. Bulletin of mathematical biology 67: 1227-1251.

18. Jones LE, Perelson AS (2007) Transient viremia, plasma viral load, and reservoir replenishment in HIV-infected patients on antiretroviral therapy. $J$ Acquir Immune Defic Syndr 45: 483-493.

19. Podsadecki TJ, Vrijens BC, Tousset EP, Rode RA, Hanna GJ (2007) Decreased adherence to antiretroviral therapy observed prior to transient human immunodeficiency virus type 1 viremia. J Infect Dis 196: 1773-1778.

20. Macias J, Palomares JC, Mira JA, Torres MJ, Garcia-Garcia JA, et al. (2005) Transient rebounds of HIV plasma viremia are associated with the emergence of drug resistance mutations in patients on highly active antiretroviral therapy. J Infect 51: 195-200.

21. Cohen Stuart JW, Wensing AM, Kovacs C, Righart M, de Jong D, et al. (2001) Transient relapses ("blips") of plasma HIV RNA levels during HAART are associated with drug resistance. J Acquir Immune Defic Syndr 28: 105-113.

22. Lee PK, Kieffer TL, Siliciano RF, Nettles RE (2006) HIV-1 viral load blips are of limited clinical significance. J Antimicrob Chemother 57: 803-805.

23. Havlir DV1, Bassett R, Levitan D, Gilbert P, Tebas P, et al. (2001) Prevalence and predictive value of intermittent viremia with combination hiv therapy. JAMA 286: $171-179$.
24. Zoufaly A, Kiepe JG, Hertling S, Hufner A, Degen O, et al. (2014) Immune activation despite suppressive highly active antiretroviral therapy is associated with higher risk of viral blips in HIV-1-infected individuals. HIV Med 15: 449-457.

25. Lambert-Niclot S, Flandre P, Valantin MA, Peytavin G, Duvivier C, et al. (2011) Factors associated with virological failure in HIV-1-infected patients receiving darunavir/ritonavir monotherapy. J Infect Dis 204: 1211-1216.

26. Boufassa F, Saez-Cirion A, Lechenadec J, Zucman D, Avettand-Fenoel V, et al (2011) CD4 dynamics over a 15 year-period among HIV controllers enrolled in the ANRS French observatory. PLoS One 6: e18726.

27. Shearer WT, Rosenblatt HM, Gelman RS, Oyomopito R, Plaeger S, et al. (2003) Lymphocyte subsets in healthy children from birth through 18 years of age: the Pediatric AIDS Clinical Trials Group P1009 study. J Allergy Clin Immunol 112: 973-980.

28. Andiman WA, Simpson BJ, Olson B, Dember L, Silva TJ, et al. (1990) Rate of transmission of human immunodeficiency virus type 1 infection from mother to child and short-term outcome of neonatal infection. Results of a prospective cohort study. Am J Dis Child 144: 758-766.

29. Fung IC, Gambhir M, van Sighem A, de Wolf F, Garnett GP (2012) The clinical interpretation of viral blips in HIV patients receiving antiviral treatment: are we ready to infer poor adherence? J Acquir Immune Defic Syndr 60: 5-11.

30. Shearer WT, Quinn TC, LaRussa P, Lew JF, Mofenson L, et al (1997) Vira load and disease progression in infants infected with human immunodeficiency virus type 1. Women and Infants Transmission Study Group. N Engl J Med 336: 1337-1342.

31. Di Mascio M, Markowitz M, Louie M, Hogan C, Hurley A, et al. (2003) Viral blip dynamics during highly active antiretroviral therapy. J Virol 77: 12165-12172.

32. Martinez V, Marcelin AG, Morini JP, Deleuze J, Krivine A, et al. (2005) HIV-1 intermittent viraemia in patients treated by non-nucleoside reverse transcriptase inhibitor-based regimen. AIDS 19: 1065-1069.

33. Easterbrook PJ, Ives N, Waters A, Mullen J, O'Shea S, et al. (2002) The natura history and clinical significance of intermittent viraemia in patients with initia viral suppression to < 400 copies/ml. AIDS 16: 1521-1527.

34. De Rossi A (2004) Virological and immunological response to antiretroviral therapy in HIV-1 infected children: genotypic and phenotypic assays in monitoring virological failure. New Microbiol 27: 45-50.

35. van Rossum AM, Fraaij PL, de Groot R (2002) Efficacy of highly active antiretroviral therapy in HIV-1 infected children. Lancet Infect Dis 2: 93-102.

36. Fraaij PL, Verweel G, van Rossum AM, van Lochem EG, Schutten M, et al (2005) Sustained viral suppression and immune recovery in HIV type 1-infected children after 4 years of highly active antiretroviral therapy. Clin Infect Dis 40 : 604-608.

37. Adje-Toure C, Hanson DL, Talla-Nzussouo N, Borget MY, Kouadio LY, et al. (2008) Virologic and immunologic response to antiretroviral therapy and predictors of HIV type 1 drug resistance in children receiving treatment in Abidjan, Cote d'Ivoire. AIDS Res Hum Retroviruses 24: 911-917.

38. Barry O, Powell J, Renner L, Bonney EY, Prin M, et al. (2013) Effectiveness of first-line antiretroviral therapy and correlates of longitudinal changes in CD4 and viral load among HIV-infected children in Ghana. BMC Infect Dis 13: 476. 